\title{
ELECTROCARDIOGRAPHIC LEFT VENTRICULAR HYPERTROPHY AMONG GAMBIAN DIABETES MELLITUS PATIENTS
}

\author{
M. JOBE ${ }^{1}$, A. KANE ${ }^{1}$, J. C. JONES ${ }^{2}$, S. PESSINABA ${ }^{1}$, B. C. NKUM ${ }^{3}$, S. ABDOU BA ${ }^{1}$, and O. A. \\ NYAN ${ }^{2}$ \\ ${ }^{1}$ Service de Cardiologie, CHU Aristide Le Dantec, Dakar, Senegal, ${ }^{2}$ Department of Medicine and Therapeu- \\ tics, School of Medicine and Allied Health Sciences, University of The Gambia, Edward Francis Small Teach- \\ ing Hospital, Banjul, The Gambia, ${ }^{3}$ Department of Medicine, School of Medical Sciences, Kwame Nkrumah \\ University of Science and Technology, Kumasi, Ghana
}

DOI: http://dx.doi.org/10.4314/gmj.v49i1.4

Corresponding Author: Dr. M. Jobe

E-mail:modoujobe@gmail.com

Conflict of Interest: None declared

\section{SUMMARY}

Background: The global prevalence of diabetes and its complications is increasing worldwide. Its role in coronary heart disease has been linked with the presence of left ventricular hypertrophy (LVH). The present study aims to determine the prevalence of electrocardiographic left ventricular hypertrophy $(\mathrm{ECG}-\mathrm{LVH})$ in adult diabetic subjects, its epidemiological and clinical correlates.

Methods: A descriptive cross-sectional study involving 534 patients was conducted at the Edward Francis Small Teaching Hospital (formerly Royal Victoria Teaching Hospital), The Gambia. Four hundred and forty patients were included using a standard questionnaire. Anthropometry, laboratory investigations and electrocardiogram were carried out. We used the Lewis, Cornell, and Sokolow-Lyon Voltage criteria to define ECG-LVH. Minitab ${ }^{\mathrm{TM}}$ statistical software version 13.20 was used for analysis.

Results: 146 (35.2\%) patients had ECG-LVH using all 3 criteria and this prevalence was higher among women being $116(79.5 \%)$. A generally high prevalence of overweight (155/37.4\%) and obesity $(119 / 28.6 \%)$ was observed among study participants, and both clinic-day systolic and diastolic blood pressure (BP) were significantly higher in those with ECG-LVH. Poor diabetes control was observed in both groups.

Conclusion: There was a high prevalence of ECG$\mathrm{LVH}$ and it is especially so with combining multiple criteria, hence the need for screening. Clinic-day hypertension was associated with ECG-LVH hence the need for diagnosing and aggressive treatment of hypertension in patients with diabetes mellitus.

Keywords: Diabetes mellitus, ECG-LVH, The Gambia, voltage criteria

\section{INTRODUCTION}

The global prevalence of diabetes mellitus (DM) continues to rise at an alarming rate. ${ }^{1}$ It is acknowledged as a principal risk factor for cardiovascular morbidity and mortality and has a heavy impact on the global health expenditure due to both its short and long term complications. ${ }^{2}$ DM is closely linked to coronary events ${ }^{3}$ and left ventricular hypertrophy (LVH) in DM patients has been widely implicated ${ }^{4,5}$ and therefore considered as a treatment target $^{5}$, as associated cardiovascular risks become normal with full regression of LVH. ${ }^{6}$ Insulin resistance and associated abnormal glucose metabolism have been implicated in many reports as a possible pathophysiological mechanism of LVH. This therefore highlights the need for the early detection of LVH in $\mathrm{DM}$ in order to institute a timely effective intervention. ${ }^{7}$

Electrocardiogram remains a cheap, useful and a widely available tool to determine $\mathrm{LVH}^{8}$ This paper aims to determine the prevalence of electrocardiographic left ventricular hypertrophy (ECG-LVH) among adult Gambian DM patients and also to determine its associated clinical factors.

\section{METHODS}

This study was conducted at the Edward Francis Small Teaching Hospital (EFSTH) in Banjul, The Gambia during routine clinic visits (on every Monday and Wednesday) from the $6^{\text {th }}$ November, 2008 to the $4^{\text {th }}$ January 2009 between the hours of $8 \mathrm{am}$ and $2 \mathrm{pm}$.

Study Population: All patients with a confirmed diagnosis of DM and who attend the medical out-patient department, EFSTH for routine care were eligible for inclusion into the study. Pregnant women and those who did not consent for inclusion were excluded. 
Subjects less than 25 years of age and those with bundle branch block were excluded from the present analysis.

Study design: cross-sectional study.

Questionnaire: a trained research field assistant in a language understood by the study participant administered a standard questionnaire designed for the purpose of the study. The questionnaire was divided into $3 \mathrm{sec}-$ tions. Section A included items on demographic details like age, sex, address, ethnicity, religion, educational level, smoking status as well as background details about the participant's DM. Occupations were coded as manual if involving mainly unskilled labour; as trades for occupations mainly involving skilled manual labour; or as non-manual. The rest were coded as others. Section B covered information about the usual medical care the patient receives (including activities at clinic visits, medications prescribed) and also evidence of diabetic foot (or feet) complication(s). Section $\mathrm{C}$ involved carrying out basic anthropometric measurements, blood pressure (BP) measurements, urine dipstick, and venous blood sampling for serum biochemistry and also obtaining a standard 12-lead surface ECG.

Blood pressure: Blood pressure and pulse rate were recorded with an Omron 705IT machine (Omron, Kyoto, Japan) with the participant in a seated position using the subject's left arm positioned at heart level. The BP was taken first when the patient enters the consulting room and after five minutes. Two measurements were done at each time and the mean of the two readings was recorded.

Anthropometry: Height was measured without footwear or headwear with the subject standing fully erect on a flat surface, with heels, buttock and shoulders flat to the height meter, and the subject looking straight ahead using a daily calibrated stadiometer (Leicester height measure, Seca 214, Birmingham, UK). Measurement was done to the nearest $0.5 \mathrm{~cm}$. Weight was measured with the subject wearing light clothing with no footwear using a digital scale (Tanita Corporation, Tokyo, Japan). The value was recorded to the nearest $0.1 \mathrm{~kg}$. Waist circumference measured at the level of the upper margin of the iliac crest, was measured to the nearest centimeter with a flexible tape. Body mass index (BMI) was defined as weight $(\mathrm{kg}) /$ height $(\mathrm{m}){ }^{2} \mathrm{We}$ used a new generation foot-to-foot bioimpedence device (Tanita TBF300GS, Tanita Corporation) to measure fat percent, fat mass, total body water (TBW) with the subject standing erect in bare feet on the bioimpedence analyzer.
Blood and urine samples: Venous blood samples were collected and analysed using a COBAS INTEGRA 400 plus analyser (Roche Diagnostics $\mathrm{GmbH}$ ) at the EFSTH laboratories for total cholesterol, high density lipoprotein cholesterol (HDL-cholesterol), low density lipoprotein cholesterol (LDL-cholesterol), triglycerides, creatinine, fructosamine, albumin and uric acid levels. Blood glucose was determined using a portable glucometer (Accu-Chek). Urine sample was also collected and urine dipstick was done for glucose and protein.

Electrocardiography: The study participants had a standard surface 12-lead ECG recorded with the patient lying supine and relaxed on a flat surface (using a Cardioline Delta 1 EKG Machine). The machine was regularly checked to ensure that it was in a proper working condition. After explaining the procedure to the patient, the ECG leads were placed according to standard practice. The paper speed was set at $25 \mathrm{~mm} / \mathrm{s}$ whilst the voltage set at $10 \mathrm{~mm} / \mathrm{mV}$. The ECG recordings were sent to Aristide Le Dantec Teaching Hospital, in Dakar, Senegal and analysed by a group of cardiology residents, supervised by an electrophysiologist with many years of experience using a specially designed protocol. The various parameters studied included the rhythm, heart rate, PR interval, presence of significant Q wave, LVH (using Lewis, Cornell, and SokolowLyon voltage criteria) and ST-T changes.

ECG-LVH was defined according to standard criteria using the mean of 3 consecutive QRS values as follows: Lewis voltage as ( $\mathrm{R}$ wave in lead 1-R wave in lead 3$)+(\mathrm{S}$ wave in lead $3-\mathrm{S}$ wave in lead 1$) \geq 1.7 \mathrm{mV}$ ${ }^{9}$ Cornell voltage as $\mathrm{S}$ wave in $\mathrm{V} 3+\mathrm{R}$ wave in aVL $\geq 2.0 \mathrm{mV}$ in women and $2.8 \mathrm{mV}$ in men $^{10}$ SokolowLyon Voltage as $\mathrm{S}$ wave in $\mathrm{V} 1+\mathrm{R}$ wave in $\mathrm{V} 5$ or $\mathrm{V} 6 \geq 3.5 \mathrm{mV}^{11}$

\section{Data Management}

The data of each participant was collected on a questionnaire which was then entered into Microsoft Excel 2007 by double entry. The data was cross-checked and all inconsistencies were corrected. The data was then transferred to and analyzed using Minitab ${ }^{\mathrm{TM}}$ statistical software version 13.20. The characteristics of patients with ECG-LVH and those without it were compared using two-sample t-test for continuous variables and Chi-square test for categorical variables. P-values of less than 0.05 were considered to be of statistical significance.

\section{Ethical Consideration}

The School of Medicine and Allied Health Sciences, University of the Gambia Research and Publication Committee approved the study protocol. 
An informed consent was obtained from each of the study participants after explanation and careful consideration by the participant signing or thumbs printing a written consent form.

\section{RESULTS}

A total of 534 patients (171 males and 363 females) took part in the study, of whom 440 (131 males and 309 females) had a standard surface ECG. Of those who had an ECG, 415 (121 males and 294 females) met criteria for inclusion in this analysis. The majority of participants, $80.3 \%$ were between the ages of 40 and 69; The actual age distribution according to age groups (25-39, 40-54, 55-69 and $\geq 70$ years) was $49(11.8 \%)$, $175(42.2 \%), 158(38.1 \%)$ and $33(7.9 \%)$ respectively.

The prevalence of ECG-LVH according to the different criteria used is shown in Table 1 . The highest prevalence was recorded with the Cornell voltage criteria. With the Lewis but especially the Cornell voltage criteria, where the number of females diagnosed was significantly higher than that of males. However, this large difference was not observed with the Sokolow-Lyon criteria.

Table 1 Prevalence of LVH in diabetic patients according to different ECG criteria

\begin{tabular}{|l|l|l|l|l|}
\hline ECG Criteria & $\begin{array}{l}\text { Male } \\
\mathrm{N}=121\end{array}$ & $\begin{array}{l}\text { Female } \\
\mathrm{N}=294\end{array}$ & $\begin{array}{l}\text { Total } \\
\mathrm{N}=415\end{array}$ & $\begin{array}{l}\text { P- } \\
\text { value }\end{array}$ \\
\hline Lewis & $9(7.4 \%)$ & $35(11.9 \%)$ & $44(10.6 \%)$ & 0.179 \\
\hline Cornell & $13(10.7 \%)$ & $89(30.3 \%)$ & $\begin{array}{l}102 \\
(24.6 \%)\end{array}$ & $<0.001$ \\
\hline Sokolow-Lyon & $15(12.4 \%)$ & $38(12.9 \%)$ & $53(12.8 \%)$ & 0.883 \\
\hline $\begin{array}{l}\text { Combined } \\
\text { criteria }\end{array}$ & $30(24.8 \%)$ & $\begin{array}{l}116 \\
(39.5 \%)\end{array}$ & $\begin{array}{l}146 \\
(35.2 \%)\end{array}$ & 0.004 \\
\hline
\end{tabular}

One hundred and forty-six (35.2\%) patients met one or more of the three standard criteria that we have used to define ECG-LVH, of whom 116 (79.5\%) were females. Among the female population studied, 116 (39.5\%) had ECG-LVH compared to 30 (24.8\%) of males.

Table 2 Clinical characteristics of diabetic patients by ECG-LV

\begin{tabular}{|l|l|l|l|}
\hline Variable & $\begin{array}{l}\text { ECG-LVH } \\
\mathrm{N}=146\end{array}$ & $\begin{array}{l}\text { No ECG- } \\
\text { LVH } \\
\mathrm{N}=269\end{array}$ & P value \\
\hline Age (years) & $52.9 \pm 11.1$ & $53.1 \pm 11.5$ & 0.910 \\
\hline Age at diagnosis (years) & $48.1 \pm 10.9$ & $47.2 \pm 12.0$ & 0.488 \\
\hline $\begin{array}{l}\text { Sex } \\
\text { Female }\end{array}$ & $116(79.5 \%)$ & $178(66.2 \%)$ & 0.004 \\
\hline Height $(\mathrm{cm})$ & $161.9 \pm 6.9$ & $162.7 \pm 8.8$ & 0.352 \\
\hline Weight $(\mathrm{Kg})$ & $73.3 \pm 13.9$ & $72.4 \pm 15.2$ & 0.564 \\
\hline BMI $\left(\mathrm{kg} / \mathrm{m}^{2}\right)$ & $28.0 \pm 5.2$ & $27.4 \pm 6.1$ & 0.352 \\
\hline History of hypertension & $97(66.4 \%)$ & $152(56.5 \%)$ & 0.056 \\
\hline Systolic BP(mmHg) & $137.5 \pm 22.5$ & $129.8 \pm 21.3$ & 0.001 \\
\hline Diastolic BP(mmHg) & $80.3 \pm 12$ & $76.5 \pm 9.5$ & $<0.001$ \\
\hline
\end{tabular}

BMI- body mass index, BP- blood pressure
As shown in Table 2, there was no significant difference in the age of patients with or without ECG-LVH both at the time of diagnosis of diabetes and also at the time of the study.

Hypertension was more prevalent among subjects with ECG-LVH but this was not statistically significant. However, clinic-day systolic and diastolic BPs were significantly more elevated among patients with ECGLVH.

Two hundred and seventy-four $(66 \%)$ of patients were either overweight $(155 / 37.4 \%)$ or obese $(119 / 28.6 \%)$. We found a significant difference between the sexes as $48(39.7 \%)$ and $9(7.4 \%)$ of males were respectively overweight and obese compared to 107 (36.4\%) and $110(37.4 \%)$ of females $(\mathrm{P}<0.001)$; indeed the distribution of subjects by BMI $(<18.5,18.5-24.9,25-29.9$ and $\geq 30)$ was $9(2.2 \%), 132(31.8 \%), 155(37.3 \%)$ and 119 $(28.7 \%)$ respectively.

However, as shown in Table 3 there was no significant statistical difference between BMIs of subjects with or without ECG-LVH. Serum creatinine and lipid profile were similar in both groups. However, serum albumin level was significantly lower among patients with ECG-LVH. In this cohort, fructosamine levels were high in both groups.

Table 3 Metabolic features of diabetic patients by ECG-LVH

\begin{tabular}{|l|l|l|l|}
\hline Variable & $\begin{array}{l}\text { ECG-LVH } \\
\mathrm{N}=146\end{array}$ & $\begin{array}{l}\text { No ECG-LVH } \\
\mathrm{N}=269\end{array}$ & $\begin{array}{l}\mathrm{P} \\
\text { value }\end{array}$ \\
\hline $\begin{array}{l}\text { Fructosamine } \\
(\mu \mathrm{mol} / \mathrm{L})\end{array}$ & $\begin{array}{l}375 \\
(363-389)\end{array}$ & $\begin{array}{l}377 \\
(368.7-385.3)\end{array}$ & 0.877 \\
\hline $\begin{array}{l}\text { Serum creatinine } \\
(\mu \mathrm{mol} / \mathrm{L})\end{array}$ & $\begin{array}{l}69.1 \\
(66.6-71.6)\end{array}$ & $\begin{array}{l}71.4 \\
(69.7-73.1)\end{array}$ & 0.433 \\
\hline Serum albumin $(\mathrm{g} / \mathrm{L})$ & $\begin{array}{l}38.9 \\
(38.4-39.4)\end{array}$ & $\begin{array}{l}40.1 \\
(39.8-40.4)\end{array}$ & 0.033 \\
\hline $\begin{array}{l}\text { Total cholesterol } \\
(\mathrm{mmol} / \mathrm{L})\end{array}$ & $\begin{array}{l}5.3 \\
(5.2-5.4)\end{array}$ & $\begin{array}{l}5.2 \\
(5.1-5.3)\end{array}$ & 0.560 \\
\hline $\begin{array}{l}\text { Serum triglycerides } \\
(\mathrm{mmol} / \mathrm{L})\end{array}$ & $\begin{array}{l}1.3 \\
(1.25-1.35)\end{array}$ & $\begin{array}{l}1.3 \\
(1.23-1.32)\end{array}$ & 0.644 \\
\hline $\begin{array}{l}\text { HDL-cholesterol } \\
(\mathrm{mmol} / \mathrm{L})\end{array}$ & $\begin{array}{l}0.87 \\
(0.85-0.89)\end{array}$ & $\begin{array}{l}0.86 \\
(0.85-0.88)\end{array}$ & 0.720 \\
\hline
\end{tabular}

Results are shown as mean and $95 \%$ CI

\section{DISCUSSION}

The prevalence of ECG-LVH using all three standard criteria (Lewis, Cornell and Sokolow-Lyon Voltage) in this study was high $(35.2 \%)$. The prevalence was higher in females compared to males using either all or any of the aforementioned criteria. Using the individual criteria, the prevalence of ECG-LVH was highest with the Cornell voltage criteria $(26.8 \%)$ and lowest with the Lewis voltage criteria (10.6\%). 
It has been demonstrated from previous studies that ECG has a lower sensitivity compared to echocardiography in determining $\mathrm{LVH}^{12}$ Generally, black individuals have greater precordial QRS voltages than whites and many of the LVH criteria have higher sensitivity in detecting LVH in blacks and lower specificity compared with whites. ${ }^{13,14}$ However, many of the criteria proposed like the Araoye for African blacks are yet to be validated and so far have offered no comparative advantage over the standard criteria. ${ }^{15}$

Additionally many factors might limit the accuracy of ECG in determining LVH including age, body habitus, obesity and chronic lung diseases. Hence many authors advocate the use of echocardiography to determine LVH. However, the availability of echocardiography is still limited and not feasible in many places especially in our sub-region. Besides the unavailability of technical expertise to operate echocardiography in many places, high costs further limits its usage. The present study compared different voltage criteria and showed the superiority of using more than one criterion to determine ECG-LVH. This is advocated by many authors and has been demonstrated in various studies. $^{16,17,18}$

We found in the present study that both systolic and diastolic BP were significantly higher in those with ECG-LVH which is consistent with the findings by Desai et $\mathrm{al}^{19}$, There is therefore the need for a more aggressive BP control. Niiranen et al found home measured blood pressure values to be more strongly associated with ECG-LVH. ${ }^{20}$ In the Cascale Monferrato study however, the prevalence of hypertension was high and systolic BP were raised in both groups (i.e. those with ECG-LVH and those without) but with no statistical difference. ${ }^{6}$

There is paucity of data regarding the relationship between low serum albumin level and LVH in DM patients which we found in our study. This needs evaluation with further studies as low serum albumin has been strongly linked to cardiovascular events in a previous study. $^{21}$

We used fructosamine to assess glycaemic control which we found to be poor in both groups but with no significant difference. This finding is similar to that in the Cascale Monferrato study where glycated hemoglobin was used as a marker for glycaemic control. ${ }^{6}$ There was a high prevalence among study participants of overweight and obesity. This is consistent with the findings in a previous study in urban Gambia. ${ }^{22}$ This, and the poor metabolic control are risks for cardiovascular complications and hence require effective intervention.
Women with DM have been shown to have a higher cardiovascular morbidity and mortality than their male counterparts. $^{23,24,25}$ Therefore the higher prevalence of females with LVH and obesity in this cohort is worrying and needs attention.

We advocate for the early detection and aggressive treatment of LVH to prevent potentially lifethreatening consequences. Many antihypertensive agents have been recommended for the treatment of LVH. However, agents with intrinsic sympathomimetic properties or with direct vasodilatory effects (e.g. hydralazine and minoxidil) must be avoided. ${ }^{26}$ The most effective agents in reducing left ventricular mass are angiotensin II receptor blockers, angiotensinconverting enzyme inhibitor, calcium channel blockers and diuretics. ${ }^{27}$ Bauml and Underwood recommend that treatment should consist of an angiotensin II receptor blocker or an angiotensin-converting enzyme inhibitor ${ }^{28}$ which have additional renoprotective effect as well as reversing LVH. However, these agents are less efficacious in blacks according to the investigators of Studies of Left Ventricular Dysfunction (SOLVED) ${ }^{29}$ but who have been shown to benefit from treatment with diuretic agents. ${ }^{26}$

\section{CONCLUSION}

We found a higher prevalence using multiple criteria to determine ECG-LVH and this prevalence was higher among females and associated with high clinic-BP. Therefore, screening, aggressive treatment for ECGLVH and associated high BP should be instituted in the standard care of DM patients.

\section{ACKNOWLEDGEMENTS}

We would like to thank all the patients who took part in the study and the staff of the medical outpatient department of the Edward Francis Small Teaching Hospital. We would like to extend our heartfelt gratitude to Mr. Eliman Jobe of the Edward Francis Small Teaching Hospital Laboratories and to Ms Musu Bojang for their special contributions to the realisation this work.

\section{REFERENCES}

1. Wild S, Roglic G, Green Anders, Sicree R, King. Global Prevalence of Diabetes, Estimates for the year 2000 and projections for 2030. Diabetes Care. 2004; 27: 1047-1053

2. Zhang P, Zhang X, Brown J, Vistisen D, Sicree R, Shaw J, Nichols G. Global healthcare expenditure on diabetes for 2010 and 2030. Diabetes Res Clin Pract. 87(3):293-301

3. Levy D, Garrison RJ, Savage DD, Kannel WB, Castelli WP. Prognostic implications of echocardiographically determined left ventricular 
mass in the Framingham Heart Study. $N$ Eng $J$ Med. 1990; 322: 1561-1566

4. Srivastava PM, Calafiora P, MacIsaac RJ, Patel SK, Thomas MC, Jerums G, Burrell LM. Prevalence and predictors of cardiac hypertrophy and dysfunction in patients with type 2 diabetes. Clin Sci (Lond). 2008; 114:313-320

5. Dawson A, Morris AD, Struthers A D. The epidemiology of left ventricular hypertrophy in type 2 diabetes mellitus. Diabetologia. 2005; 48:19711979

6. Bruno G, Giunti S, Bargero G, Ferrero S, Pagano $\mathrm{G}$, Perin PC. Sex-differences in prevalence of electrocardiographic left ventricular hypertrophy in Type 2 diabetes: The Casale Monferrato Study. Diabet Med. 2004; 21: 823-828

7. Dawson A, Struthers A D. Screening for treatable left ventricular abnormalities in diabetic patients. Expert Opin Biol Ther. 2003; 3(1):107-112

8. Nkum BC, Nyan O, Corrah T, Ankrah TC, Allen S, Micah FB, McAdam K. Resting electrocardiographic and echocardiographic findings in an urban community in The Gambia. Journal of Science and Technology (Ghana). 2009; 29(1):130-140

9. Lewis T. Observations upon ventricular hypertrophy with special reference to preponderance of one or another chamber. Heart. 1914; 5: 367-403.

10. Cascale PN, Devereux RB, Alonso DR, Campo E, Kligfield P. Improved sex-specific criteria of left ventricular hypertrophy for clinical and computer interpretation of electrocardiograms: validation with autopsy findings. Circulation. 1987; 75(3):565-72.

11. Sokolow M, Lyon TP. The ventricular complex in left ventricular hypertrophy as obtained by unipolar precordial and limb leads. Am Heart J. 1949; 37: 161-86.

12. Somaratne JB, Whalley GA, Poppe KK, ter Bals MM, Wadams G, Pearl A, Bagg W, Doughty RN. Screening for left ventricular hypertrophy in patients with type 2 diabetes mellitus in the community. Cardiovasc Diabetol. 2011; 10:29.

13. Chapman JN, Mayet J, Chang CL, Foale RA, Thom SA, Poulter NR. Ethnic differences in the identification of left ventricular hypertrophy in the hypertensive patient. Am J Hypertens. 1999;12(5):437-42

14. Okin PM, Wright JT, Nieminen MS, Jern S, Taylor AL, Phillips R, Papademetriou V, Clark LT, Ofili EO, Randall OS, Oikarinen L, Viitasalo M, Toivonen L, Julius S, Dahlöf B, Devereux RB. Ethnic differences in electrocardiographic criteria for left ventricular hypertrophy: the LIFE study. Losartan Intervention For Endpoint. Am J Hypertens. 2002; 15 (8):663-71.
15. Dada A, Adebiyi AA, Aje A, Falase AO. Comparison of Araoye's criteria with standard electrocardiographic criteria for diagnosis of left ventricular hypertrophy in Nigerian hypertensives. West Afr J Med. 2006; 25(3):179-85.

16. Hameed W, Razi MS, Khan MA, Hussain MM, Aziz S, Habib SS, Aslam M. Electrocardiographic diagnosis of left ventricular hypertrophy: comparison with echocardiography. Pak J Physiol. 2005; 1(1):35-38

17. Erice B, Romero C, Andériz M, Gorostiaga E, Izquierdo M, Ibáñez J. Diagnostic value of different electrocardiographic voltage criteria for hypertrophic cardiomyopathy in young people. Scand $J$ Med Sci Sports. 2009; 19: 356-363.

18. Song A, Li TC, Wang NL, Liang YB, Peng Y. Better criterion screening for left ventricular hypertrophy by electrocardiogram with different purposes. African Journal of Microbiology Research. 2011; 5(14) :1740-1746

19. Desai CS, Ning H, Lloyd-Jones DM. Competing cardiovascular outcomes associated with electrocardiographic left ventricular hypertrophy: the Atherosclerosis Risk in Communities Study. Heart. 2012; 98:330-334.

20. Niiranen TJ, Jula AM, Kantola IM, Karanko $\mathrm{H}$, Reunanen A. Home-measured blood pressure is more strongly associated with electrocardiographic left ventricular hypertrophy than is clinic blood pressure: the Finn-HOME study. J Hum Hypertens. $2007 ; 21$ (10):788-794.

21. Kuller LH, Eichner JE, Orchard TJ, Grandits GA, McCallum L, Tracy RP. The relation between serum albumin levels and risk of coronary heart disease in the Multiple Risk Factor Intervention Trial. Am J Epidemiol. 1991; 134(11):1266-77

22. van der Sande MAB, Ceesay SM, Miligan PJM, Banya WAS, Prentice A, McAdam KPWJ, Walraven GEL. Obesity and Undernutrition and Cardiovascular Risk Factors in Rural and Urban Gambian Communities. Am J Public Health. 2001; 91(10):1641-1644

23. Tenenbaum A, Fisman EZ, Schwammenthal E, Adler Y, Benderly M, Motro M, Shemesh J. Increased prevalence of left ventricular hypertrophy in hypertensive women with type 2 diabetes mellitus. Cardiovasc Diabetol. 2003; 2:14

24. Marks JB, Raskin P. Cardiovascular risk in diabetes: a brief review. J Diabetes Complications. 2000; 14:108-115

25. Galcera-Tomas J, Melgarejo-Moreno A, GarciaAlberola A, Rodriguez-Garcia P, Lozano-Martinez J, Martinez-Hernandez J, Martinez-Fernandez S. Prognostic significance of diabetes in acute myocardial infarction. Are the differences linked to female gender? Int J Cardiol. 1999; 69:289-298. 
26. Liebson PR . Left ventricular hypertrophy. Curr Treat Options Cardiovasc Med. 1999;1:219-230

27. Lip GYH. Regression of Left Ventricular Hypertrophy and Improved Prognosis. Circulation. 2001; 104:1582-1584

28. Bauml MA, Underwood DA. Left ventricular hypertrophy: An overlooked cardiovascular risk factor. Cleve Clin J Med. 2010; 77: 381-387
29. Exner DV, Dries DL, Domanski MJ, Cohn J. Lesser response to angiotensin-converting-enzyme inhibitor therapy in black as compared with white patients with left ventricular dysfunction. $N$ Engl J Med. 2001; 344:1351-1357-31 